\title{
Assessing sustainability and strengthening operational policies: the SUSTAIN project
}

\author{
Caroline Salthouse ${ }^{1}$, Alan Pickaver ${ }^{2}$, Maria Ferreira ${ }^{2}$ \\ ${ }^{1}$ North West Coastal Forum Secretariat email: caroline.salthouse@4nw.org.uk; ${ }^{2}$ Coastal \& Marine \\ Union (EUCC) email: a.pickaver@eucc.net; m.ferreira@eucc.net
}

The increasing intensity of human activities along our coastline (viz. the development of ports and harbours, coastal protection, land reclamation, tourism and sand/gravel extraction) has a severe impact on coastal communities and natural habitats. The EC has adopted a renewed EU Sustainable Development Strategy. It aims at bringing about a high level of environmental protection, social equity and cohesion, economic prosperity and active promotion of sustainable development worldwide. There are multiple inter-linkages between the key challenges: for example between the use of renewable energy and climate change.

Local and regional authorities are making efforts to use ICZM planning approaches to lead to sustainable development. A number of actions need to be implemented along the coast to improve sustainability. Therefore, it is important to know where improvements are needed. The criteria which will be developed and tested in SUSTAIN will provide the management policy tool which is most needed and currently lacking.

The key objective of SUSTAIN is to have in place a fully implementable policy tool, applicable for all 22 coastal states of the EU, which will ensure that the integrated management of coastal issues will be sustainable. This entails the agreement within the project, of a set of criteria which are readily measurable and which cover both the threats of an unsustainable development and the opportunities provided by a sustainable future which faces all coastal authorities and communities throughout Europe.

The results from the project will be presented at an international conference, to be held in Autumn 2012 in Sefton. This offers an opportunity to showcase the achievements of the North West and for partners within the region to learn from others across the EU.

The project partnership is led by the Coastal \& Marine Union (EUCC), Netherlands and includes partners from 9 other EU countries including Cyprus, France, Germany, Greece, Ireland, Italy, Portugal, Slovenia and Spain, with Sefton Borough Council and Down District Council representing the UK. The project partnership includes a mix of local and regional authorities, research institutions and NGOs.

Reference:

For more details see the project website http://www.sustain-eu.net

This is an Open Access article distributed under the terms of the Creative Commons Attribution-Noncommercial License 3.0, which permits unrestricted use, distribution, and reproduction in any noncommercial medium, provided the original work is properly cited. 